\title{
ANTHROPOMETRIC AND ANAEROBIC PROFILE OF ELITE WOMEN BASKETBALL PLAYERS
}

\author{
T. Tsankov* \\ Department "Basketball, Volleyball, Handball”, Faculty of Pedagogy, National Sports Academy \\ „Vassil Levski“, Sofia, Bulgaria
}

\begin{abstract}
Changes in the levels and the dynamics in the development of anaerobic capabilities are of utmost importance in basketball - a sport with intermittent and speed-strength characteristics. The objective of the study is to establish the anthropometric and anaerobic profile of elite basketball players from the national team of women up to 20 years of age. This profile will help the future selection, forecasting and the refinement of the training methodology for the preparation of elite basketball players of this age group, In order to solve the identified tasks, we have used the following methods of study: anthropometrics, BMI, cycle-ergometrics, and mathematics-statistical methods (variational and correlations analyses). As a result of the carried-out training process, between the two tests we have noticed statistically reliable changes in the AcTM (active total body mass), PRMM (percentage of the muscle mass out of the total), PP (peak power), and AnP (average anaerobic power).

Based on the conducted research, a model was created for the assessment of the studied morphofunctional indicators and the anaerobic capabilities of under-20 y.o. women basketball players, for their participation in a European Championship.
\end{abstract}

Key words: basketball, anthropometrics, speed-strength endurance, motive efforts, anaerobic potential

\section{INTRODUCTION}

Modern-days basketball is extremely dynamic and is constantly developing and improving. The continuous intensifying of the game imposes ever higher requirements towards the players' athleticism and speed-strength potential. Keeping track of the level and the dynamics of development of the anaerobic capacity is very important in basketball, which is among the sports with intermittent and speed-strength characteristics. The specific speed-strength endurance is of significant importance for contemporary basketball however, there is no substantial data for the dynamics and the variations among women a basketball player.

Studying these correlations will help optimize the training practice process and the condition

Tsanko Tsankov, Faculty of Pedagogy, Department "Basketball, Volleyball, Handball”. National Sports Academy ,, Vassil Levski“, Sofia, address: Studentski grad, Acad. Stefan Mladenov 21 str., 1700 Sofia,Bulgaria,e-mail: tz_tzankov@abv.bg, phone: +359893338670 preparation, as well as the functional potential, through the different stages of several years of training the basketball players.

With this as objective, we have set ourselves the task to discover the variation in the correlation between anthropometric and anaerobic characteristics among women basketball players during their preparation to take part in a European Championship. We believe that this would help the future refinement and scientific argumentation of the training methodologies for the management of the training and coaching process in basketball. The study and the tracking of the results of such studies are informative and of great significance for the training work with elite basketballers in the future. In this way, there will be prerequisites established for the improvement of the functional abilities of future basketballers, as well as their better technical-tactical preparedness and competition performance.

The role of securing scientific methodology and control in sports is growing in 
significance. The extremely high competition among adolescent female basketball players when participating at European championships defines the need to develop systems of highly informative tests and performance indicators, which will assess basketballers' condition through each stage of their sports preparation.

Control in sports, as a scientific category, has occurred and has been systematically improving, in relation to delivering information about the status of a specific object or system, and through feedback targeting to optimize the management and coaching process.

In literature, "control" means "managing", while in sports primarily, the term "control" itself is used a synonym to "managing". The control system in the sports area includes three subjects - measuring, assessment, optimization (1). These are three inter-related and complementary sub-systems of control which ensure the delivery of the necessary information for managing the training and competition processes.

Maintaining and keeping the speed-strength endurance and explosive capabilities during separate matches or tournaments within 10 days, is of utmost significance for the competitive performance in basketball.

The problem with the competitive performance of women basketballers from national teams of different ages, and assessment of their preparedness through a comparative analysis of the indicators of their physical development, specific work capabilities, and game efficiency, are subjects in the studies of (2-5).

The overall development of the motive capabilities in basketball sets the question of the assessment and control of the specific functional training of the players. The introduction of heart rate metrics had a significant contribution in this direction; control over La, BE, VO2 max and other biochemical and physiological indexes.

The objective of the study is to establish a profile and model for assessment after tracing of the changes in morpho-functional parameters and anaerobic abilities among women basketball players of the national team under 20 years of age, during their preparation for taking participation in a European Championship.

\section{METHODS}

In order to track down the anaerobic capabilities and anaerobic power of the players in the adolescent women's national team, we have used one of the most popular and commonly used worldwide anaerobic tests "Wingate". It possesses proven reliability and validity for assessing the anaerobic power (6). The Wingate Anaerobic Test (WAnT) is a short-term maximal intensity cycle ergometer test, which provides anaerobic mechanical power output variables. Despite the physiological significance of the variables extracted from the WAnT, the test is very intense, and generally applies for athletes.

The study was conducted in a laboratory environment, in the National Centre Dianabad. The "Wingate" test is completed by using bicycle-ergometer (stationary bicycle) 984E, Monark Exercise AB, Sweden, and a specialized software with it. The test consists of 30 seconds pedalling with maximum power, at resistance rate of 0,075 per a kilogram of the body mass. The tested players from the national team were briefed in advance with the essence of the test and the way it would be performed, and instructed to pedal as fast as they can. They were also verbally motivated while doing the tests. The anthropometric performance indicators of the adolescent female basketball players were tracked down in laboratory environment at the Dianabad National Sports Centre.

The tests were run in two flights - in the morning before breakfast, and 14 basketball players took part. The first test was performed on 30.05.2014, at the beginning of the preparation camp for participation in the European Championship, and the second test was done on 27.06.2014, at the end of the preparation phase, just before the start of the European Championship. The study protocol was conducted in agreement with the players who have a contract with Bulgarian basketball federation for participation in European championship women under 20.

In order to solve the set tasks, we have used the following methods of exploration: anthropometrics, cycle-ergometrics, and mathematics-statistical methods (BMI, variational and correlations analyses).

\section{RESULTS}

Table 1 below shows the list of the abbreviations used hereafter in the text, which 
were the selected parameters used in order to find solutions to the set tasks and for the objective of the current study.

Table 1. Abbreviations of the main tested parameters

\begin{tabular}{|l|l|l|}
\hline TESTS AND PARAMETERS & Abbreviation & Unit of measurement \\
\hline Total body mass & TM & $\mathrm{kg}$ \\
\hline Active body mass & ATM / AcTM & $\mathrm{kg}$ \\
\hline Body fat & BF & $\%$ \\
\hline Body mass index & BMI & $\%$ \\
\hline Muscle mass & MM & $\%$ \\
\hline Muscle circumference upper arm & MCA & $\mathrm{cm}$ \\
\hline Muscle circumference thigh & MCT & $\mathrm{cm}$ \\
\hline Maximum muscle power (peak power) & PP & Watt \\
\hline Average power & AP & Watt \\
\hline Coefficient of exhaustion (percentage of power decline) & PrPD & $\%$ \\
\hline
\end{tabular}

For our study, we have selected the following parameters: TM - total body mass; AcTM active body mass; PRBF - percentage of the body fat; BMI - Body mass index; PRMM muscle mass percentage; MCA - muscle circumference of the upper arm; MCT muscle circumference of the thigh; Peak Power (PP) - the maximum power; AnP (Average Power, AP) - the average exercised power during the whole test; and PrPD (Power Decline $=($ Peak Power - Min Power $) \times 100 \%)$, a parameter which is used to define the socalled Fatigue Index. The fatigue index is used to measure the exhaustion of the anaerobic energy capacity at maximum motive efforts.

To evaluate the Body Mass Indexes of the researched basketball players, we used the adapted table recommended by the World
Health Organization for establishing the degree stoutness of the body (7). Body Mass Indexes is calculated based on measured height and weight with accuracy $0,01 \mathrm{~kg} / \mathrm{m}^{2}$.

The variance in the tested anthropometric parameters, and in those which give information and characterize the dynamics in the anaerobic power capacities of the tested national team basketball players - women under 20 years old, are exhibited in Table 2. and Table 3.

The first test shows the basketball players being with normal body weight $\mathrm{BMI}=22,27 \%$. Results vary between $19,80 \%$ and $22,79 \%$. Only one basketball player is overweight $-\mathrm{BMI}=25,45 \%$.

Table 2. Variations in the anthropometric parameters and anaerobic power-first test

\begin{tabular}{|l|l|l|l|l|l|l|l|l|l|l|}
\hline $\begin{array}{l}\text { Tested } \\
\text { parameters } \\
\begin{array}{l}\text { Statistical } \\
\text { measures }\end{array}\end{array}$ & TM $\Rightarrow$ & ATM & BF & BMI & MM & MCA & MCT & PP & AP & PrPD \\
\hline X & 68,01 & 54,41 & 19,58 & 22,27 & 41,67 & 22,15 & 54,36 & 548,69 & 398,95 & 54,96 \\
\hline S & 9,27 & 5,72 & 4,96 & 1,58 & 1,80 & 1,18 & 2,95 & 80,85 & 59,71 & 6,90 \\
\hline Me & 68,3 & 53,55 & 20,1 & 22,45 & 41,9 & 22,15 & 55,45 & 554,7 & 394,5 & 55,75 \\
\hline As & $-0,04$ & 0,30 & $-0,36$ & 0,36 & 0,02 & 0,20 & $-0,75$ & $-1,55$ & 0,15 & $-0,31$ \\
\hline Ex & $-0,32$ & $-0,88$ & $-0,64$ & 1,02 & 0,79 & $-0,80$ & 0,11 & 4,71 & 1,92 & $-1,22$ \\
\hline R & 30,8 & 16,8 & 15,8 & 5,65 & 6,6 & 3,6 & 9,3 & 318,9 & 230,1 & 20,5 \\
\hline X min & 52,3 & 46,5 & 11,1 & 19,8 & 38,4 & 20,5 & 48,5 & 349,2 & 284,7 & 44 \\
\hline X max & 83,1 & 63,3 & 26,9 & 25,45 & 45 & 24,1 & 57,8 & 668,1 & 514,8 & 64,5 \\
\hline V \% & 13,63 & 10,51 & 25,33 & 7,11 & 4,32 & 5,33 & 5,43 & 14,76 & 14,97 & 12,55 \\
\hline d & 0,58 & $-1,33$ & 1,22 & 0,21 & $-0,69$ & $-0,26$ & $-0,27$ & $-32,80$ & $-86,23$ & $-7,51$ \\
\hline $\mathrm{t}$ & $-1,69$ & $-6,58$ & 3,92 & $-1,89$ & $-1,68$ & $-1,28$ & $-0,47$ & $-1,88$ & $-2,79$ & $-1,70$ \\
\hline P \% & 87,50 & 99,98 & 99,65 & 90,90 & 87,33 & 76,68 & 35,05 & 95,77 & 97,90 & 87,74 \\
\hline
\end{tabular}


Table 3. Variations in the anthropometric parameters and anaerobic power-second test

\begin{tabular}{|l|l|l|l|l|l|l|l|l|l|l|}
\hline $\begin{array}{l}\text { Tested } \\
\text { parameters } \\
\begin{array}{l}\text { Statistical } \\
\text { Yheasures }\end{array}\end{array}$ & TM $\lesseqgtr$ & ATM & BF & BMI & MM & MCA & MCT & PP & AP & PrPD \\
\hline X & 68,59 & 55,74 & 18,36 & 22,48 & 42,36 & 22,41 & 54,63 & 616,20 & 431,75 & 62,47 \\
\hline S & 8,82 & 5,56 & 4,97 & 1,58 & 1,77 & 1,08 & 3,08 & 52,63 & 27,48 & 15,65 \\
\hline Me & 68,25 & 54,5 & 19,45 & 22,71 & 42,3 & 22,55 & 55,65 & 625,56 & 429,62 & 64,90 \\
\hline As & $-0,12$ & 0,31 & 0,05 & 0,60 & 0,37 & $-0,34$ & $-0,86$ & $-0,35$ & 0,88 & $-0,31$ \\
\hline Ex & $-0,50$ & $-0,98$ & $-0,10$ & 1,69 & $-1,08$ & $-1,17$ & 0,41 & $-0,86$ & 1,27 & $-1,32$ \\
\hline R & 28,1 & 16,2 & 16,8 & 5,63 & 5 & 3,2 & 10,4 & 160,39 & 96,22 & 45,86 \\
\hline X min & 53,4 & 47,8 & 10,5 & 20,22 & 40 & 20,7 & 48,5 & 533,65 & 393,54 & 37,42 \\
\hline X max & 81,5 & 64 & 27,3 & 25,85 & 45 & 23,9 & 58,9 & 694,04 & 489,76 & 83,28 \\
\hline V \% & 12,86 & 9,97 & 27,07 & 7,05 & 4,18 & 4,82 & 5,64 & 8,54 & 6,36 & 25,05 \\
\hline $\mathrm{d}$ & 0,58 & $-1,33$ & 1,22 & 0,21 & $-0,69$ & $-0,26$ & $-0,27$ & $-32,80$ & $-86,23$ & $-7,51$ \\
\hline $\mathrm{t}$ & $-1,69$ & $-6,58$ & 3,92 & $-1,89$ & $-1,68$ & $-1,28$ & $-0,47$ & $-1,88$ & $-2,79$ & $-1,70$ \\
\hline P \% & 87,50 & 99,98 & 99,65 & 90,90 & 87,33 & 76,68 & 35,05 & 95,77 & 97,90 & 87,74 \\
\hline
\end{tabular}

During the second test, the women from the national basketball team again have normal weight $-\mathrm{BMI}=22,48 \%$. This time their results range from $20,22 \%$ to $23,16 \%$. Again, one player has overweight indicator $\mathrm{BMI}=25,85 \%$.

The values of the coefficient of variation on the signs characterizing the anthropometric indicators and the indicators of the "Wingate" test: Peak Power(PP) - the maximum power, AnP (Average Power, AP) - the average tested power of the whole test, show strong uniformity of the sample in the first test $(14,76 \%-14,97 \%)$.
In the parameter Percentage of Body Fat (PrBF) it is satisfactory uniform $(25,33 \%)$. In the second test, the values of the variation coefficient keep their strong uniformity, as in the tested group we notice variation in the coefficient of fatigue index - from $12,55 \%$ to $25,05 \%$.

Table 4. and Table 5. show the correlation matrices and the summarized data of the correlation analysis of the two tests, which were run during the preparation training of the basketball players who were at that time included in the women under 20 national team. Based on the correlation analysis, the following interdependencies were discovered between the parameters picked for the needs of this study.

Table 4. Correlation matrix - first test

\begin{tabular}{|l|l|l|l|l|l|l|l|l|l|l|}
\hline & TM & ATM & $\%$ BF & BMI & $\%$ MM & MCA & MCT & PP (w) & AP (w) & PD \\
\hline TM & 1 & & & & & & & & & \\
\hline ATM & 0,917 & 1 & & & & & & & & \\
\hline \% BF & 0,699 & 0,360 & 1 & & & & & & & \\
\hline BMI & 0,647 & 0,339 & 0,918 & 1 & & & & & & \\
\hline \%MM & $-0,689$ & $-0,511$ & $-0,736$ & $-0,605$ & 1 & & & & & \\
\hline MCA & 0,686 & 0,539 & 0,620 & 0,790 & $-0,325$ & 1 & & & & \\
\hline MCT & 0,854 & 0,726 & 0,732 & 0,738 & $-0,650$ & 0,579 & 1 & & & \\
\hline PP(w) & $-0,005$ & $-0,089$ & 0,112 & 0,093 & 0,447 & 0,071 & 0,122 & 1 & & \\
\hline AP(w) & 0,191 & 0,058 & 0,299 & 0,226 & 0,225 & 0,093 & 0,318 & 0,909 & 1 & \\
\hline PD(\%) & $-0,389$ & $-0,370$ & $-0,230$ & $-0,335$ & 0,469 & $-0,445$ & $-0,184$ & 0,523 & 0,496 & 1 \\
\hline
\end{tabular}


Table 5. Correlation matrix - second test

\begin{tabular}{|l|l|l|l|l|l|l|l|l|l|l|}
\hline & TM & ATM & $\%$ BF & BMI & $\%$ MM & MCA & MCT & PP (w) & AP (w) & PD \\
\hline TM & 1 & & & & & & & & & \\
\hline ATM & 0,898 & 1 & & & & & & & & \\
\hline$\%$ BF & 0,688 & 0,303 & 1 & & & & & & & \\
\hline BMI & 0,573 & 0,196 & 0,941 & 1 & & & & & & \\
\hline \%MM & $-0,589$ & $-0,524$ & $-0,447$ & $-0,422$ & 1 & & & & & \\
\hline MCA & 0,759 & 0,664 & 0,540 & 0,556 & $-0,230$ & 1 & & & & \\
\hline MCT & 0,777 & 0,492 & 0,904 & 0,911 & $-0,479$ & 0,658 & 1 & & & \\
\hline PP(w) & 0,350 & 0,229 & 0,404 & 0,348 & $-0,336$ & $-0,083$ & 0,503 & 1 & & \\
\hline AP(w) & 0,558 & 0,559 & 0,259 & 0,154 & 0,007 & 0,536 & 0,413 & 0,512 & 1 & \\
\hline PD $(\%)$ & 0,072 & $-0,164$ & 0,454 & 0,460 & $-0,050$ & $-0,218$ & 0,463 & 0,749 & 0,075 & 1 \\
\hline
\end{tabular}

We have noticed a high level of dependency between parameter ATM (active body mass) and TM (total body mass), with values $\mathrm{r}=0,917$, as well as between AP (the average exercised power) and PP (the peak power) $r=0,909$. In the ranges of high dependency, we have also found that between MCT (muscle circumference of the thigh) and total body mass TM - r $=0,854$, and with AcTM r $=0,726$, also with \% BF $r=0,732$. Statistically significant dependencies are noticed in 6 relations, while moderate dependencies have 7 relations of the selected parameters.

In the second test, just before the participation of the basketball players in the European Championship, the dependency is very high between: MCT and \% BF - r=0,904. High dependency is shown between ATM and TM $\mathrm{r}=0,898$; MCA and TM - r=0,759; MCT and TM - r=0,777; PD and PP - $r=0,749$. Out of the rest of the tested parameters, we found out that there is increase in the number of dependencies between the other parameters - 11 have significant and 9 have moderate dependency rates.

The Table 6. presents a model for assessment of the morpho-functional indicators and the anaerobic capabilities of elite basketball players from the national team - women up to 20 y.o.

Table 6. Table for assessment of the morpho-functional and the anaerobic indicators

\begin{tabular}{|l|l|l|l|l|l|l|l|l|l|l|}
\hline ASSESSMENTS & TM & ATM & BF & BMI & MM & MCA & MCT & PP & AP & PrPD \\
\hline Excellent & 86,23 & 66,86 & 28,30 & 25,64 & 45,90 & 24,57 & 60,79 & 721,46 & 486,71 & 93,77 \\
\hline Very good & 77,41 & 61,30 & 23,33 & 24,06 & 44,13 & 23,49 & 57,71 & 668,83 & 459,23 & 78,12 \\
\hline Good & 68,59 & 55,74 & 18,36 & 22,48 & 42,36 & 22,41 & 54,63 & 616,20 & 431,75 & 62,47 \\
\hline Average & 59,77 & 50,18 & 13,39 & 20,90 & 40,59 & 21,33 & 51,55 & 563,57 & 404,27 & 46,82 \\
\hline Poor & 50,95 & 44,62 & 8,40 & 19,32 & 38,82 & 20,25 & 48,47 & 510,94 & 376,79 & 31,17 \\
\hline
\end{tabular}

\section{CONCLUSION}

The parameters: Peak Power (PP) - the maximum power a tested sports player can exercise during a "Wingate" test, is usually demonstrated during the first (or the second) 5seconds intervals of the test duration. It is assumed that it can be used to assess the capacity of the alactate anaerobic system (the capacity of the so-called adenosine triphosphate - creatine phosphate system).

AnP (Average Power, AP) - the average power realized throughout the whole test. It is accepted, that it can be used for overall assessment of the capacity of the alactate and the lactate anaerobic energy-efficient systems (i.e. of the adenosine triphosphate - creatine phosphate and the lactate systems).

PrPD $($ Power Decline $=($ peak power $-\min$ power) $\mathrm{x} 100 \%$ ) - is a parameter which is used to define the so-called Fatigue Index. The fatigue index is used to assess the exhaustion of the anaerobic energy capacity at maximum motive efforts.

The results and the analysed data from the variational and correlation analysis of the two 
studies on the indicators selected for our study, give us reason to interpret and draw appropriate conclusions regarding the same, i.e. the conclusions drawn will be statistically reliable. At the average values of anthropometric indicators, an improvement is observed at the second testing for all of the examined traits. Backed up with the necessary statistical reliability, we can observe this on the active body mass and the body fat percentage.

The comparison of the results from the two tests gave us the grounds to conclude that as a consequence of the used and applied training methods, there is improvement in the conditioning preparedness of the women basketball players. During the studied preparation period, an increase in active body mass, endurance and strength of the lower limbs was observed in the entire population of female basketball players studied, which was demonstrated through the Peak Power (PP) measured in Watts (W), as well as improvement in the alactate and lactate anaerobic energy-efficient systems, and the Average Power (AP) - the average of the exercised power throughout the whole test. The anthropometric and anaerobic profile of elite basketball players from the women's national team up to 20 years of age will set up the conditions for improvement, and will assist in the future the selection, the forecasting and the precision in the training methodology for preparation of elite basketballers.

\section{REFERENCES}

1. Zhelyazkov, Tz, and Dasheva, D. Basics of sport training. Gerra Art, Sofia, 2010.

2. Tzankova, J. Relationship between the sports preparedness and the game realization of the national team - women 20. Research in Kinesiology, International Journal of Kinesiology and Other Related Sciences, vol.42, №2, ISSN 1857-8942, pp 205-208, 2014.

3. Tsankov, Ts. and Tsankova, J. Research on the competitive performance of the Bulgarian National team of under-16 female players in the European Championship, Division B in 2012. SPORT MONT, XI (37,38,39), ISSN 1451-7485, pp 534-541, 2013.

4. Tzankova-Kaloyanova, M. Average values and variation of basic sings of competitive efectiveness of 15-16 years old basketball players. Sport \& Science Magazine, №6, ISSN 1310-3303, pp 64-70, 2018.

5. Peltekova, I. Approbation of the test for measuring the specific basketball performance - "SPARQ" in bulgarian conditions. Second International Scientific Conference "Optimization and inovation in the training process", "St. Kliment Ohridski”, ISSN 1314-2275, pp 167-177, 2010.

6. Inbar, O., Bar-Or, and Skinner, J. The Wingate anaerobic test. Human kinetics, Champaign (Ill), 1996.

7. Petkov, S., Toteva, M. and Maznev, I. Practical exercises on sport medicine, NSA, Sofia, 2012. 